January 2015

\title{
The Tumblarians
}

Tamarack Hockin

San Jose State University, tamahoc@gmail.com

Follow this and additional works at: https://scholarworks.sjsu.edu/ischoolsrj

Part of the Scholarly Communication Commons, and the Scholarly Publishing Commons

\section{Acknowledgements}

A version of this article was originally written to fulfill the requirements of LIBR 200, Information Communities, taught by Dr. Michael Stephens, as part of the MLIS program at San Jose State University's School of Information.

\section{Recommended Citation}

Hockin, T. (2016). The Tumblarians. School of Information Student Research Journal, 5(2). https://doi.org/ 10.31979/2575-2499.050206 Retrieved from https://scholarworks.sjsu.edu/ischoolsrj/vol5/iss2/6

This article is brought to you by the open access Journals at SJSU ScholarWorks. It has been accepted for inclusion in School of Information Student Research Journal by an authorized administrator of SJSU ScholarWorks. For more information, please contact scholarworks@sjsu.edu. 


\title{
The Tumblarians
}

\begin{abstract}
This paper examines the tumblarians as an information community and discusses community membership, information behaviours, and complementary models for a situated understanding of this unique personal-professional community. A review of the literature concerning LIS bloggers is presented as a complement to the tumblarians, who have no in depth treatment in the research as yet. Characteristics particular to the tumblarians are explored through informal conversation with a community member, and Fisher, Unruh, and Durrance's (2003) information communities model is employed to provide a deeper understanding of the information behaviour of the tumblarians. This paper offers suggestions for future research based on the preliminary findings of the tumblarians as LIS bloggers and a virtual community.
\end{abstract}

\section{Keywords}

tumblarians, biblioblogosphere, LIS bloggers, information communities, virtual communities

\section{Acknowledgements}

A version of this article was originally written to fulfill the requirements of LIBR 200 , Information Communities, taught by Dr. Michael Stephens, as part of the MLIS program at San Jose State University's School of Information.

\section{About Author}

Tamarack Hockin is a first year MLIS candidate at the San Jose State University School of Information, and a public library technician working in information services and new media. Tamarack's research interests include transliteracy, informal and self-directed learning in libraries, and discourse within the LIS professions. 
Blogging has changed. While various iterations of blogging technology have coexisted online for years - from homegrown, to Blogger, to Wordpress - there are emerging new microblogging services which call into question the relationship of the technology to the genre, and to the communities which use them. For more than a decade the LIS blogosphere has been investigated by numerous researchers seeking to describe the shape and structure of the blogosphere, as well as the players and their communities.

Enter tumblr, and enter the tumblarians [sic]. The term, tumblarians, is a combination of tumblr and librarians. Bound by use of their hashtag of the same name, the tumblarians share information, connect socially, and even maintain community listings (Tkacik, 2012). A virtual community centered topically around librarianship, the tumblarians may be the newest additions to the LIS blogosphere - or they may be something completely different. Tumblr inhabits a unique middle ground, serving as "a social network, a blogosphere and social media simultaneously" (Chang, Tang, Inagaki, and Liu, 2014, p. 28), and the tumblarians are heretofore unexplored in the LIS literature.

In seeking a deeper understanding of the tumblarians, this paper explores how they fit within the existing LIS literature, what defining characteristics may be suggested, and which models of community may be applicable. Building on a body of research regarding the LIS blogosphere, this paper provides preliminary examination into the tumblarians: a new community of LIS-topical microbloggers.

\section{Literature Review}

\section{Tumblr in the Research}

Tumblr is still a new technology relative to scholarly research and publishing cycles, and only two relevant references were found in the LIS literature. Power (2014) offered an indexing of select LIS-topical blogs on tumblr, but treatment was limited to brief descriptions and the article provided no discussion or directions for research. In a recent conference publication, Rose (2013) discussed preliminary research exploring the functions of hashtag use on tumblr. Rose's final research was unpublished at the time of writing, but preliminary findings suggested metacategories of contributing to discourse, contributing to community, organizing information, and expressing emotion.

As a platform, tumblr may be considered a type of hybrid which enables both blogging (as evidenced by the language used by both the tumblr site and literature which describes the site's functionality) as well as functions more strongly associated with social media. In considering the tumblarians as bloggers, research concerning the LIS blogosphere may be considered most analogous. Blogging has already undergone substantial format changes while continuing to be discussed holistically in the literature. In How Blogging Software Reshapes the Online Community, Blood (2004) discussed substantial changes to the nature of blogs and the blogging community as popular free software made blogging more accessible to those unable to code HTML. While the communicative purpose of tumblr cannot be assumed as the same as other blogs, tumblr is identified as a type of blogging (Chang et al., 2014) and the language associated with tumblr (e.g., blog, posts, tags, comment) shows substantial overlap with other blogging platforms. 


\section{The LIS Blogosphere}

A review of the literature concerning the LIS blogosphere revealed both a body of research focused largely on description and classification, and other research concerned with the bloggers themselves and their community. Of the former, BarIlan $(2004 ; 2007)$ and Aharony $(2009 a ; 2009 b ; 2010)$ provided foundational structural analyses of LIS blogs which focused on aspects of classification: topical analysis and content classification of posts, comments, metadata, and other descriptive statistics. Nardi, Schiano, Gumbrecht, and Swartz's (2004) popular article, Why We Blog, and Stephens' (2008) research of LIS bloggers provided a counterpoint in the research by examining more in depth the bloggers themselves, their contexts and motivations,.

Stephens' (2008) survey of the LIS blogosphere revealed a personalprofessional hybrid genre of LIS bloggers who were both motivated and rewarded by professional development a sense community in the blogosphere. Finlay, Hank, Sugimoto, and Johnson (2013) supported the assertion of community between LIS bloggers with an analysis of LIS blog linking structures. Finlay et al found that personal-professional LIS blogs had greater interconnectedness (more linkages, and more linkages across clusters) than institutional blogs, and comprised more of the blogosphere (both in number of blogs, and by having largest networks).

Respondents in Stephens' (2008) research understood the LIS blogosphere as a community, and acknowledged that this community manifested both positive and negative impacts. Greenland (2013) elaborated on this discussion, and identified that in addition to the benefits of communication afforded by the community, LIS bloggers faced challenges regarding privacy, and the negotiation of personal and work identities. Powers (2008) explored this further in an examination of ethical discourse in the LIS blogosphere.

Complemented by the research of Kjellberg (2009), who discussed academic blogs as a situated genre, the LIS blogosphere may be understood as a type of grey literature for the profession. This comparison is made directly in Finlay et al. (2013) and Powers (2008), and Stephens' (2008) pragmatic biblioblogger model similarly proposed the LIS blogosphere as a new manifestation of professional practice. An understanding of blogging as grey literature reaffirms the LIS blogosphere as community, and supports the relevance for further consideration in the research.

\section{The Gap: Looking For the Tumblarians}

Research concerning LIS bloggers provides a complement for understanding the tumblarians as a blogging community. Informal discussion with a member of the tumblarian community and casual review of content posted with the tumblarian hashtag seem to reveal a consistency with the context and motivations of bloggers revealed by Stephens (2008): A personal-professional hybrid genre, which emphasizes professional development and discourse. There are parallels in format as noted by Finlay et al (2013) who described heavy interlinking between librarians' personal-professional blogs: The tumblarians are inherently linked 
through their use of hashtags, which may be used to track conversation, or coordinate real-time online meetups.

The decision to focus on the tumblarians as information community was in part informed by the relevant wealth of literature regarding LIS bloggers. While the biblioblogosphere remains active and prolific, new technologies have been popularized since the bulk of research in this area was published circa 2005-2008. Researchers continue to examine the biblioblogosphere, but microblogging services such as twitter and tumblr (the latter inconsistently considered a microblogging platform) have begun to be discussed in the literature as technology platforms available for content creation. Identified as a form of blogging, microblogging services may be considered as analogous to traditional blogging platforms, such as homegrown systems (as discussed by Blood, 2004) and popular free platforms (e.g., Wordpress, Blogger). A search of the LIS literature for reference to the tumblarians incorporated multiple databases, including Web of Science and LIS specific databases, and a gap was identified in regards to depth of research regarding tumblr. References to tumblr found in the LIS literature were limited to descriptive annotations of tumblarian blogs (Power, 2014) and grey literature providing early stage examinations of blog linkages and the use of hashtags (Rose, 2013). With this gap identified, the next step led to direct interaction with the information community. The following sections will provide an informal investigation and literature-based examination of the defining features of the tumblarians' community.

\section{Community Investigation}

In considering a member of the tumblarian community who may provide insight and directions for further understanding of the tumblarians, a colleague from a nearby city, herein referred to as SM, was identified as an accessible and legitimate community member. SM can be considered a legitimate community member because SM self-identifies as a member of the community, regularly interacts with the community through tangible content creation (e.g., public blog posts tagged with the tumblarians hashtag), and is listed in the community index of tumblarians maintained by Tkacik (2012).

A one-time conversation between the researcher and SM took place using Skype teleconferencing on March 9, 2015. An informal discussion with SM described participation mechanics on tumblr, and characteristics of the tumblarian community as perceived and experienced by SM. The discussion with SM was recorded using TalkHelper, a third party recording application for Skype, allowing for later transcription by the researcher. The recording and transcription were reviewed, and informal coding suggested four themes in the discussion. These themes were reinforced by informal review of tumblarian blog content (i.e., posts on tumblr tagged as tumblarians or tumblarian). However, no formal interview or survey instrument was constructed, and themes identified are within the context of an informal discussion between known colleagues. While themes from this conversation cannot be interpreted as legitimate research findings, many of SM's comments and descriptions suggest the possibility of thematic areas for further exploration, and are discussed in following sections in relation to Fisher, Unruh, and Durrance's (2003) information communities. 
Discussion with SM suggested a need for further review of the literature. A combination of search methods, including berrypicking techniques such as footnote chasing and citation searching (Bates, 1989), were used to explored research related to Fisher and Durrance's (2003) information communities concept. The literature was explored primarily using Google Scholar as a federated search tool, and numerous databases from the San Jose State University Library were accessed. This exploration and review of the literature enabled a deeper discussion of the tumblarians as an information community.

\section{Discussion}

\section{Themes from Discussion with a Community Member}

Following informal discussion with tumblarian community member SM, a review of the conversation recording and transcription revealed four themes:

- The tumblarian community as an entry point.

- Tumblarian membership and content is diverse, and includes libraries, librarians, and other users.

- Tumblarians may engage with multiple tumblr communities, of which the tumblarians are only one.

- The tumblarian community provides a place which can be returned to for sharing content, seeking information, or strengthening community through social engagement.

The tumblarian community as an entry point. The conversation with SM began with a discussion of the tumblarians' listing, or index, maintained by Tkacik (2012). SM described the list as a community resource and entry point to engaging with other librarians on tumblr, and emphasized that the list was not a defining border of the tumblarian community. SM suggested that the list could be used to discover librarians to follow (i.e., subscribe to a feed of their blog posts), hence curating a personalized feed of tumblarians and other tumblr users. The list was an entry point in that it indexed self-identified librarians whose profiles could be followed (subscribed to) and which provided further access, through links and hashtags, to other tumblr blogs of interest to SM.

When questioned about what types of information SM may have been seeking via use of the tumblarian community, SM identified contact with practicing professionals during the earliest stages of her career as extremely valuable. SM talked about how the tumblarians provided links to a real-world context of the profession while SM was at university pursuing an MLIS. The tumblarian community provided an entry into the profession beyond the geographical communities of work and university, and SM was able to see what librarians in diverse regions were doing at their workplaces.

Tumblarian membership and content is diverse, and includes libraries, librarians, and other users. While discussing Tkacik's (2012) list, SM described a very open definition of membership in the tumblarian community. SM suggested that membership could be understood as including both content creators and consumers. When SM identified value in the ability to observe other practitioners' reflections on their practice, including details of their workplace projects, this was an example of membership through content (information) consumption. 
SM characterized Tkacik's (2012) list as including libraries, librarians, and other users. An informal review of posts using the tumblarians hashtag supported SM's assertion of a diverse community. Users of the hashtag included libraries (institutions), as well as individual librarians, library workers, and LIS students. Other community members did not identify as with any library category. While these members may have undeclared affiliations with libraries or librarianship, some identified themselves as working in other professions.

That some members were not library-affiliated may be understood in light of the diverse content shared by the tumblarians. Content, as well as membership, was a blend of library-centric and other posts. SM discussed this diversity as central and defining of the tumblarians, noting that while library-centric content was certainly fundamental, the inclusion of other, non library-centric content was a strong and consistent theme in posts and member interests.

Tumblarians may engage with multiple tumblr communities, of which the tumblarians are only one. Related to the diversity of content within the tumblarian community was the possibility of community and interest overlap on the tumblr platform. SM emphasized that users engage with multiple interest-based communities on the tumblr platform, and mentioned fandoms repeatedly as an example. The use of hashtags in particular allows users to simultaneously engage with multiple interest-based communities (e.g., tumblarians and Harry Potter for a Harry Potter fandom). The degree to which other interests may be considered communities is beyond the scope of this paper, but is discussed here as a unique feature of the tumblarians as community situated within the tumblr platform. Tumblr's use of hashtags was a repeated item of discussion with SM, and appears to be a central and defining feature of the platform itself.

Because librarians may belong to multiple communities on the tumblr platform, non-library themed interests may overlap with interests of other community members. As such, content tagged as tumblarians may not always relate to libraries. SM discussed how community and interest overlap may serve to strengthen the tumblarian community by defining more niche interests shared by members. In an informal review of tumblarian posts, this overlap and inclusion of both library-centric and other content was reflected in the community as a whole, and on individual members' blogs. While some tumblarian blogs posted almost exclusively about library-centric content, others, including SM's own blog, presented a mix of personal and professional content.

The tumblarian community provides a place which can be returned to for sharing content, seeking information, or strengthening community through social engagement. While $\mathrm{SM}$ is consistently active on the tumblr platform, SM discussed participating in the tumblarian community irregularly or inconsistently. SM's comments seemed to suggest the tumblarian community as most engaging for new users (i.e., an entry point), where engagement may be highest at the initial encounter and lessen over time. After an initial familiarizing period, the tumblarian community may become a place to return to periodically as part of overall tumblr use.

SM discussed using the tumblarians tag for occasional information seeking, giving one example of a request for advice concerning an upcoming job interview. 
SM characterized the tumblarian community as a low-barrier venue for discussion and information seeking. SM also gave examples of times when the tumblarians hashtag may be more active as users occasionally coordinate synchronous blogging (e.g., real-time during live events, or pre-arranged times for synchronous individual screening of a film or show). SM's own tumblarian interests seemed to depend on information encountering in other spheres (including work or school, and also other tumblr communities), which would lead to irregular content sharing or information seeking.

\section{Discussion of the Tumblarians as Information Community}

Seeking to further understand the information behaviour of the tumblarians, and the role which information plays in the community, the work of Fisher, Unruh, and Durrance (2003) provide a framework for consideration. In a two year study of three community networks, Fisher, Unruh, and Durrance proposed a model of information communities (ICs) defined by five characteristics which can be applied here to a discussion of the tumblarians.

Characteristics 3, 4, \& 1: "Information communities effectively exploit the information sharing qualities of emerging technologies and yield multiplier effects for stakeholders" (Fisher, Unruh, \& Durrance, 2003, p. 301), "Information communities transcend barriers to information-sharing" (p. 302), and "Information communities emphasize collaboration among diverse information providers" ( $\mathrm{p}$. 300).

Fisher, Unruh, and Durrance's (2003) multiplier effects identified the potential for ICs to work beyond boundaries by including multiple groups, agencies, and individuals representing a diversity of backgrounds, geography, and service areas. Applied to the tumblarians, there are instances of in-person meetups of community members at professional conferences which showcase the community's potential to operate both geographically and virtually. Diverse library types are represented in the community, bringing together academic, special, and public librarians as well as archivists, cataloguers, and more. Fisher, Unruh, and Durrance suggested that by their large scope, ICs may pull in new members, hence multiplying both potential information sources (contributing members) and potential information reach as the community scales. A meta-anecdotal example may be found in the connection which allowed the researcher and community member (SM) to connect through locality, bringing a new, potential community member (the researcher) into contact with the virtual IC.

Fisher, Unruh, and Durrance's (2003) discussion of technology identified characteristics which have, since their writing more than a decade ago, come to be innately associated with social media and Internet forums: a centralized place online which can be accessed anonymously (e.g., under pseudonym), asynchronously, and which enables niche information sharing. The ability to link diverse users across geography is again an innate potential of Internet connectivity. These characteristics certainly shape discourse and engagement in the tumblarians community, but may also be understood as common to other virtual communities.

Characteristic 2: "Information Communities anticipate and often form around people's needs to get and use information" (Fisher, Unruh, \& Durrance, 2003, p. 301). 
In differentiating ICs from other types of virtual communities, Fisher, Unruh, and Durrance (2003) stressed that while subject focus may vary there must be a common interest and a defined information need. The topical aspect will be discussed in this section, whereas the information need will be more fully explored in conjunction with Characteristic Five (section below).

In the case of the tumblarian IC, topical commonality is expressed in part by the hashtag: a combination of tumblr (the platform) and librarian. Career advice, workplace experiences, program development, and professional discourse in the community are all related back to librarianship. Discussion with SM diverged from Fisher, Unruh, and Durrance (2003) where SM identified overlapping communities of interest, and multiple themes in the tumblarian community. In addition to librarianship, fandom was identified as a key component of the IC. Further study would be needed to clarify whether fandom elements worked in conjunction with librarian-topical content (e.g., pop culture imagery captioned with some idea or message related to librarianship), or whether fandom appeared distinct from librarianship but using the tumblarian hashtag.

Fisher, Unruh, and Durrance (2003) made a point to distinguish ICs from other virtual communities, yet other discussions of virtual community also include some treatment of information use. Burnett (2000), in an examination of information behaviour in virtual communities, discussed how information neighbourhoods develop to meet information needs. According to Burnett, overlapping interests allow members to anticipate information needs in complementary areas:

Because virtual communities function within a general context of shared interests participants tend to be aware of what information is of potential interest to others, and can, thus, share that information without necessarily going through the formalities of querying an information retrieval system. (An environmental model of human information behaviour section, para. 7).

Burnett identified a theme related to Fisher, Unruh, and Durrance's need for topical similarity: By constructing a community around a subject theme, a situation may be created in which relevant information may be shared as matter of course and may meet unstated, ambient information needs of community members. Both Burnett's virtual communities and Fisher, Unruh, and Durrance's ICs identify sharing pertinent information as an element of community definition. However, Burnett's information neighbourhood de-emphasized the concept of purposive information seeking. In place of the centrality of information seeking, Burnett discusses the community aspects of virtual communities, and how social relationships create a space where information sharing may thrive.

Characteristic 5: "Information communities connect people and foster social connectedness" (Fisher, Unruh, \& Durrance, 2003, p. 303).

Fisher, Unruh, and Durrance (2003) identified social connectedness as distinct from the connections made by information alone, but did not strongly link social connectedness to concepts of community. According to Fisher, Unruh, and Durrance's (2003) model, the tumblarians may be understood as fostering social connectedness simply as a result of the technology used: commenting, reblogging, 
tagging users and following feeds. Fisher, Unruh, and Durrance's treatment of community is more information-centric than social or communicative, and offers little basis for insight into how to consider the relationships between the tumblarians as individuals and members of a community, or how the tumblarians may interact with and create meaning from information.

Burnett (2000) reflected on the role of virtual communities as social and interpersonal spaces, and more deeply explored the types of information behaviour which may be facilitated by virtual community. Integrating Savolainen's everyday life information seeking (ELIS), Burnett (2000) suggested that virtual communities facilitate information scanning and the orienting facet of ELIS by providing a social space in which information is more likely to be serendipitously encountered. Burnett's framework appears to more accurately reflect the centrality of social aspects in an information community. While the tumblarians meet Fisher, Unruh, and Durrance's (2003) criteria for consideration as an IC, there remains strong indication from discussion with SM that social relationships play an important part in the formation of the tumblarians' community. This aspect remains relatively unaddressed in Fisher, Unruh, and Durrance's model.

\section{Conclusion}

Future research into the tumblarians as an information community may consider information behaviour in light of the social context in which they occur. Related research by Turner and Fisher (2006), building on the IC model of Fisher, Unruh, and Durrance (2003), examined newsgroup information communities for evidence of social roles, and subsequently proposed a model of four social types in ICs. Their types, members, mentors, managers, and moguls, may provide a framework for future research into the social roles of the tumblarians.

Future research may also build on the information aspect of Fisher, Unruh, and Durrance's (2003) model, and the LIS literature offers numerous and significant contributions of information researchers who discuss and define models of information-seeking behaviour. However, further considerations of the tumblarians' information use behaviour may benefit from a model which addresses synchronous or collaborative information use and creation. Buckland's multitype understanding of information may offer a conceptual framework for these discussions. Buckland proposes that information may be understood as allpervasive - indicating knowledge, the process of understanding, and the structures formed along with the creation of it (Bates, 2009). A constructionist perspective may also be useful here in considering information behaviour and systems as constructed within a social discourse (Talja, Tuominen, \& Savolainen, 2005).

Future research may also, and even simultaneously, consider the social constructs of the new LIS blogosphere (inclusive of the tumblarians) and its implications for practice and scholarship. A thorough examination of the tumblarians has not been possible within the scope of this paper, and so the treatment of the tumblarians as a community has been explored in two ways: 1) through themes revealed during informal conversation with a community member, and 2) in applying Fisher, Unruh, and Durrance's (2003) model of information communities. What findings may be extrapolated from this paper suggest that there

are both social and informational aspects to the tumblarian community, and that the 
community is both defined topically by its professional focus (librarianship) and its inclusion of other, non-professional content. These characteristics suggest a strong likeness to the LIS blogosphere as found in the review of the literature, and may indicate possible further research into the current LIS blogosphere which could include the tumblarians.

\section{References}

Aharony, N. (2009a). An exploratory analysis of librarians' blogs: Their development, nature and changes. Aslib Proceedings, 61(6), 587-604. doi:10.1108/00012530911005535

Aharony, N. (2009b). Librarians and information scientists in the blogosphere: An exploratory analysis. Library \& Information Science Research, 31(3), 174181. doi:10.1016/j.lisr.2009.02.001.

Aharony, N. (2010). LIS blog comments: An exploratory analysis. Libri, 60(1), 6577. doi:10.1515/libr.2010.006.

Bar-Ilan, J. (2004). Blogarians - A new breed of librarians. Proceedings of the American Society for Information Science and Technology 67th Annual Meeting, 41, 119-128.

Bar-Ilan, J. (2007). The use of weblogs (blogs) by librarians and libraries to disseminate information. Information Research 12(4). Retrieved from http://informationr.net/ir/12-4/paper323.html

Bates, M. (1989). The design of browsing and berrypicking techniques for the online search interface. Retrieved from http://comminfo.rutgers.edu/ tefko/Courses/e530/Readings/Bates_Berrypi cking.pdf

Bates, M. (2009). Information. Encyclopedia of Library and Information Sciences, Third Edition. doi:10.1081/E-ELIS3-120045519

Blood, R. (2004). How blogging software reshapes the online community. Communications of the ACM, 47(12), 53-55.

Burnett, G. (2000). Information exchange in virtual communities: A typology. Information Research, 5(4). Retrieved from http://www.informationr.net/ir/5-4/paper82.html

Chang, Y., Tang, L., Inagaki, Y., \& Liu, Y. (2014). What is tumblr: A statistical overview and comparison. ACM SIGKDD Explorations Newsletter Special Issue on Big Data, 16(1), 21-29. doi:10.1145/2674026.2674030

Finlay, S. C., Hank, C., Sugimoto, C. R., \& Johnson, M. (2013). The structure of the biblioblogosphere: An examination of the linking practices of institutional and personal library blogs. Journal of Web Librarianship, 7(1), 20-36. doi:10.1080/19322909.2012.714305

Fischer, K. E., \& Durrance, J. C. (2003). Information communities. In K. Christensen \& D. Levinson (Eds.), Encyclopedia of community: From the village to the virtual world. doi:10.4135/9781412952583.n248

Fisher, K. E., Unruh, K. T., \& Durrance, J. C. (2003). Information communities: Characteristics gleaned from the studies of three online networks. Proceedings of the American Society for Information Science and Technology, 40(1), 298-305. 
Greenland, K. (2013). Negotiating self-presentation, identity, ethics, readership and privacy in the LIS blogosphere: A review of the literature. Australian Academic \& Research Libraries, 44(4), 217-225. doi:10.1080/00048623.2013.843236

Kjellberg, S. (2009). Scholarly blogging practice as situated genre: An analytical framework based on genre theory. Information Research, 14(3), 1-13. Retrieved from http://www.informationr.net/ir/14-3/paper410.html

Nardi, B. A., Schiano, D. J., Gumbrecht, M., \& Swartz, L. (2004). Why we blog. Communications of the ACM, 47(12), 41-46.

Power, J. L. (2014). Tumblr. Journal of Access Services, 11(2), 91-96. doi:10.1080/15367967.2014.898567

Powers, A. C. (2008). Social networking as ethical discourse: Blogging a practical and normative library ethic. Journal of Library Administration, 47(3-4), 191-209. doi:10.1080/01930820802186522

Rose, S. M. (2013). There is a conversation in my search: Differing uses for tags. Proceedings of The 21st International BOBCATSSS Conference, (pp. 2831). Ankara: Turkey.

Stephens, M. (2008). The pragmatic biblioblogger: Examining the motivations and observations of early adopter librarian bloggers. Internet Reference Services Quarterly 13(4), 311-345. doi:10.1080/10875300802326475.

Talja, S., Tuominen, K., \& Savolainen, R. (2005). "Isms" in information science: Constructivism, collectivism, and constructionism. Journal of Documentation, 61(1), 79-101. doi:10.1108/00220410510578023

Tkacik, K. (2012). Tumblrarian 101: Tumblr for libraries and librarians. Retrieved from: http://www.thedigitalshift.com/2012/08/social-media/tumblrarian101-tumblr-for-libraries-and-librarians/

Turner, T. C., \& Fisher, K. E. (2006). The impact of social types within information communities: Findings from technical newsgroups. Proceedings of the 39th Hawaii International Conference on System Sciences, 6. doi:10.1109/HICSS.2006.471 